\title{
How to Reach and Influence Both Users and Non-users of Internal Social Media Technologies
}

\author{
Kristen Werling and Michaela Maier
}

\section{ABSTRACT}

This study investigates potential barriers and supporting factors for employees' Internal Social Media (ISM) usage intention for not only users but also the harder to reach target group of non-users. Following and extending the Decomposed Theory of Planned Behavior (DTPB), it is assumed that ISM acceptance, superiors' and peers' support of ISM, superiors' and peers' usage of ISM, and the perceived ISM usage ability will explain employees' usage intention. Multiple regression analyses revealed that users' and non-users' usage intention increases mostly with acceptance. Additionally, for users, peer usage support and behavior, as well as ISM Trainings showed to have an impact on usage intention.

Keywords: Decomposed Theory of Planned Behavior, Internal Organizational Communication, Internal Social Media, Organizational Behavior, Perceived Organizational Communication Quality.

\section{INTRODUCTION}

In today's changing business world, technologies like never before play one of the most crucial roles in business operations and improving organizational competitiveness (Benitez, Chen, Teo, \& Ajamieh, 2018; Benitez, Llorens, \& Braojos, 2018). Many organizations have placed a top priority on becoming digital in business processes (Urbach \& Röglinger, 2019) and are considering the possible consequences of not only offering but also not offering social media tools within the organization. For example, in offering social media tools within the organizations, organizations can improve the speed and ease of communication as well as improved transparency, engagement, collaboration, innovation, and knowledge management (Ewing, Men, \& O’Neil, 2019; Jallow, Demian, Anumba, \& Baldwin, 2017; Khalili et al., 2019; Khatri, 2019; Leidner, Gonzalez, \& Koch, 2018; Madsen, 2018). However, consequences of not offering social media tools for internal usage could be that employees seek external alternatives for internal use and thereby potentially leave the organization open to data security risks (Werling, 2020). Many companies have already implemented such technologies within their organizations, and many others are now following in their footsteps. These technologies have been referred to with various names, such as Enterprise Social Media, Enterprise2.0, Intranet2.0, Social Intranet to name a few (Janes, Patrick, \& Dotsika, 2014; Leonardi, 2014, 2015; Leonardi, Huysman, \& Steinfield, 2013; Riedl \& Betz, 2012; Williams, Hausmann, Hardy, \& Schubert, 2013); however, for purposes of this paper, these technologies will be referred to as Internal Social Media (ISM) technologies and are defined as any interactive tool or

\author{
Submitted : January 11, 2022 \\ Published : February 18, 2022 \\ ISSN: 2507-1076 \\ DOI: $10.24018 /$ ejbmr.2022.7.1.1263 \\ K. Werling* \\ Institute for Communication Psychology \\ and Media Education, University of \\ Koblenz-Landau, Landau, Germany. \\ (e-mail: werling.kn@ gmail.com) \\ M. Maier \\ Institute for Communication Psychology \\ and Media Education, University of \\ Koblenz-Landau, Landau, Germany. \\ (e-mail: mmaier@uni-landau.de) \\ *Corresponding Author
}

platform, within a secured network, behind an organization's firewall used for information exchange.

Previous research has focused on the additional value that can be created by using ISM (i.e., improved transparency, engagement, collaboration, innovation, knowledge management, and the speed and ease of communication) (Ewing et al., 2019; Jallow et al., 2017; Khalili et al., 2019; Khatri, 2019; Leidner et al., 2018; Madsen, 2018). While this research is important in identifying how ISM technologies can benefit organizations, the usage of such technologies is often voluntary in organizations. In such cases, it is crucial to identify what drives or hinders employees to use ISM technologies. Moreover, if employees do not adopt and use the ISM technologies that were implemented, it is essential to understand the reasons behind this averseness and how employees can be influenced into using them. If such barriers are not identified, organizations run the risk of wasting or spending unnecessary funds and end up with a tool that does not support what is actually needed or wanted. As such motivating and hindering factors for employees' ISM usage behavior is complex, it is important to take a holistic approach from various aspects. Research has shown that multiple factors can influence employees' intention to adopt a certain behavior, such as employees' attitudes, social norms, and the perceived ability to adopt the new behavior (Jimmieson, Peach, \& White, 2008). Hence, the purpose of the present study was to investigate potential barriers or supporting factors for employees' intention to use ISM technologies. Furthermore, this study looks at both users' and non-users' intention to use ISM technologies allowing for a unique perspective in identifying factors that can better influence the harder-to-reach target group of non-users. In taking such an 
approach, we aim to answer the research question, 'What are motivating and hindering factors for users' and non-users' intention to use ISM technologies?'.

\section{A. State of the Research}

Social media as an internal application in organizations has become of increasing interest over the past few years especially since the COVID-19 pandemic. Research in this field of interest has mainly looked at the added value and/or problems in using ISM within organizations (El Ouirdi, El Ouirdi, Segers, \& Henderickx, 2015; Leonardi, 2014, 2015; Leonardi et al., 2013; Treem, 2015). For example, the use of these new technologies can bring large benefits to corporations wishing to improve efficiency levels (Jallow et al., 2017; Khatri, 2019) by helping to reduce the everincreasing problem of communication and making it not only easier and faster to communicate with other employees, but also having access to relevant information and knowledge (Khalili et al., 2019; Leonardi, 2014, 2015; Madsen, 2018; Oostervink, Agterberg, \& Huysman, 2016). Additionally, ISM platforms can also support organizations in changing from a traditional one direction or minimal interaction communication style associated with traditional intranets to a multiple direction and interactive communication style (Ewing et al., 2019; Leidner et al., 2018). This research shows that these technologies are relevant and of value for organizations; however, if employees do not use these technologies, then the added value becomes irrelevant. Since it is already known that these technologies add value, it is of interest what drives or hinders employees in using them. Although there is little research regarding ISM usage, a recent study looked at two different types of ISM usage, consumptive and contributive usage (Chin, Evans, Liu, \& Choo, 2020), which looked at how employees use ISM but not why. Taking all of this into consideration, this research gap as to why employees either choose to use or not use ISM after their implementation is crucial for the success of these technologies.

When organizations implement ISM technologies, they attempt to influence employees to change their behaviors to integrate the usage of these new technologies into their internal communication media selection. Current research shows that the Theory of Planned Behavior (TPB) (Ajzen, $1985,1991)$ is a well-established theory that is used in various disciplines for behavioral intention predictions (Carfora et al., 2019; Chan et al., 2019; Li, Figg, \& Schüz, 2019; Sommestad, Karlzén, \& Hallberg, 2019). The TPB attempts to predict behavior with the previously mentioned factors: behavioral intention, attitude towards the behavior, social norms regarding the behavior, and control factors concerning the behavior. The TPB was further developed for technology adoption with the Technology Acceptance Model (TAM) (Davis, 1989; Davis, Bagozzi, \& Warshaw, 1989) and has been often used in determining user acceptance and usage behavior for various technologies (King \& He, 2006; Venkatesh, Morris, Davis, \& Davis, 2003). The TPB and TAM are competing models and theories which attempt to predict usage intention of technologies (Taylor \& Todd, 1995). The TAM attempts to go into more detail in determining acceptance by focusing on the perceived usefulness and the perceived ease of use of a technology as well as control factors by focusing on the ability to use a technology (Davis, 1989; Davis et al., 1989), but does not address social norms or control factors which could influence usage adoption. However, TPB addresses social norms and control factors but does not address the unique perspective of technology usage. Regarding this dilemma, the Decomposed Theory of Planned Behavior (DTPB) (Taylor \& Todd, 1995) attempted to combine both the TPB and the TAM by using the TPB as a basis for predicting intention but decomposes the core constructs attitude, social norms, and behavioral control conditions from the TPB with the fundamental concept of technology adoption from the TAM (Taylor \& Todd, 1995; Venkatesh et al., 2003). Thus, in using the DTPB, it is possible to combine the influencing factors: ISM usage intention, ISM acceptance, social norms regarding ISM usage, and ISM usage ability into one theoretical model. Nevertheless, previous research has shown that social norms can be looked at from two different perspectives - injunctive and descriptive norms - and have different impacts on behaviors (Alm, Schulze, von Bose, \& Yan, 2019). Thus, our theoretical model uses the DTPB and extends the DTPB to include both injunctive and descriptive social norms (see Figure 1). The attributes of each of these factors will be described in further detail in the following.

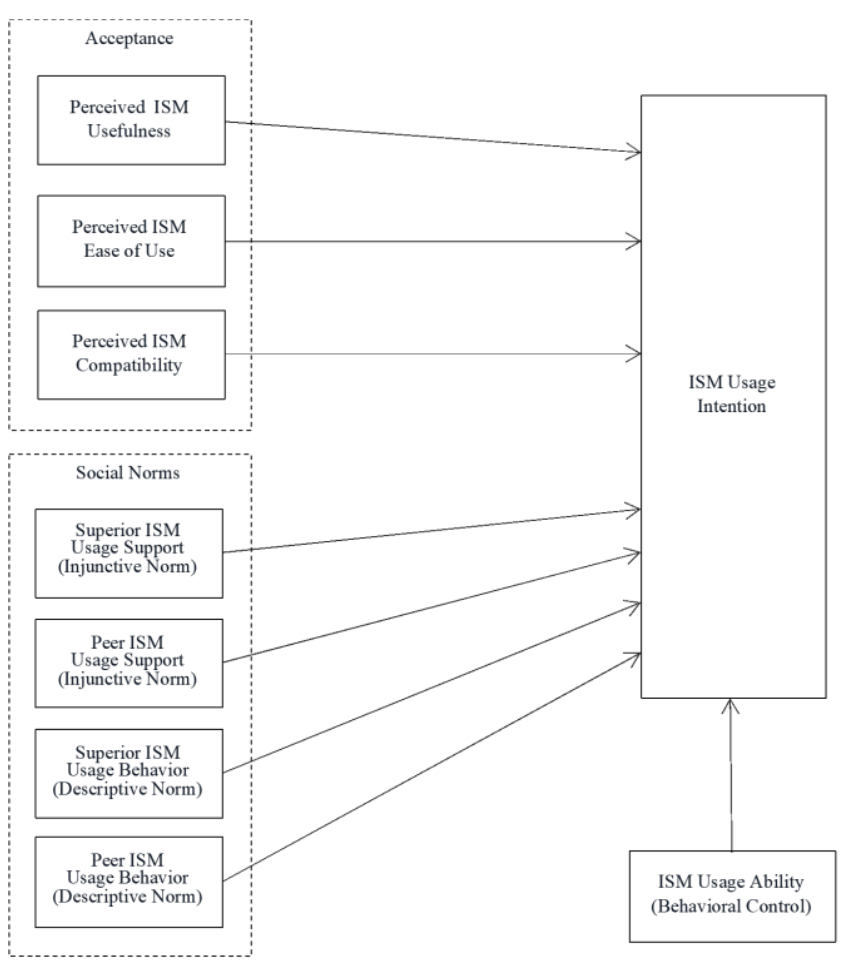

Fig. 1. Adapted and extended DTPB theoretical model.

First of all, behavioral intention looks at how likely one is to perform a certain behavior and is considered to be the main predicting factor for actual behavior (Ajzen, 1991). In technology and media usage research, behavioral intention is referred to as usage intention (Taylor \& Todd, 1995; Venkatesh et al., 2003). As measuring and observing actual employee behavior in organizations is extremely difficult (e.g., due to financial constraints for data gathering and/or allowance from organizations and their workers' counsels) (Lebek, Uffen, Neumann, Hohler, \& Breitner, 2014), this study focuses on usage intention as the dependent variable. 
Second, attitude looks at a person's opinion and perception toward a certain behavior (Ajzen, 1991) and is considered the most influencing factor in predicting behavioral intentions (Robbins \& Judge, 2018). In media and technology usage research, attitude is referred to as one's acceptance of the media or technology in question (Schneider, Aehling, Maier, \& Bacherle, 2010; Taylor \& Todd, 1995; Venkatesh et al., 2003). In regard to technology adoption, acceptance is comprised of one's perceived usefulness, ease of use, and compatibility of the technology in question (Taylor \& Todd, 1995; Venkatesh et al., 2003). Several recent studies showed user acceptance of technology systems to have an impact on usage intention of those technologies (Lin \& Lin, 2019; Prinsloo, 2018; Regmi, Zhang, Khanal, Zhang, \& Kim, 2019). If these technologies are viewed positively and beneficial, employees are more likely to use them (Lin \& Lin, 2019) leading to the first hypothesis:

H1: The higher the perceived (a) usefulness of ISM, (b) ease of use of ISM, and (c) compatibility of ISM, the higher the intention to use ISM will be.

Third, as people are sensitive to social pressures, social norms from relevant groups in one's social circle can have an impact on influencing a person's intention to change their behavior (Alm et al., 2019). Social norms can be looked at from two different dimensions: injunctive and descriptive norms (Alm et al., 2019). Injunctive norms describe what we believe is socially acceptable with the intrinsic goal of social approval (Jacobson, Mortensen, \& Cialdini, 2011). In regards to ISM, injunctive norms would be the perceived usage support of these technologies. Descriptive norms on the other hand describe what we believe that others around us do or what behavior is considered normal with the intrinsic goal that we are behaving correctly (Jacobson et al., 2011). Concerning ISM, descriptive norms would be the perceived usage behavior of ISM technologies. Although it might seem that whatever is normally done is also socially acceptable, this is not always the case; these norms can in fact conflict with each other (Jacobson et al., 2011; Smith et al., 2012). As there is a research gap in distinguishing these social norms to separately identify the effects of both injunctive and descriptive norms, injunctive and descriptive norms will be taken individually into consideration. Furthermore, social norms can entail different social perspectives, such as different social circles or groups. Previous research shows that in regards to organizational behavior and communication, the important stakeholder subgroups: superiors - consisting of direct superiors and upper management - and peers - consisting of direct colleagues and other employees - can significantly influence employees' behavior (Kandlousi, Ali, \& Abdollahi, 2010; Karanges, Johnston, Beatson, \& Lings, 2015; Neves \& Eisenberger, 2012; van Vuuren, de Jong, \& Seydel, 2007). By differentiating between these groups, it can be better understood if one group can have more influence on employees' usage intention of ISM. Hence, these social subgroups will be taken into consideration for both injunctive and descriptive social norms leading to the second hypothesis:
H2: The higher the (a) superiors' perceived usage support (superior injunctive norm) of ISM, (b) peers' perceived usage support (peer injunctive norm) of ISM, (c) superiors' perceived usage behavior (superior descriptive norm) of ISM, and (d) peers' perceived usage behavior (peer descriptive norm) of ISM, the higher the intention to use ISM will be.

Fourthly, behavioral controls look at the perceived ability to perform the behavior in question (Ajzen, 1991). Regarding technology adoption, behavioral controls entail both the internal behavioral control self-efficacy and the external control facilitating resources. Self-efficacy focuses on one's ability to independently use the technology in question (Taylor \& Todd, 1995) and can have a significant effect on one's intention to use the technology (Cheng, 2019). However, it is just as important that employees feel that they have the external facilitating resources, such as necessary technical resources and trainings for those technologies (Venkatesh \& Bala, 2008). It is possible that facilitating resources become an influencing factor for usage intention only if they are considered to be lacking (Taylor \& Todd, 1995). In a recent study concerning ISM technologies, employees felt confident that they could use these technologies independently and that they had all of the technical resources necessary to use these technologies; however, employees still expressed the desire to participate in training courses to learn about the potential benefits for using these technologies (Werling, 2020) leading to the third hypothesis:

H3: The higher the perceived ISM usage ability, the higher the intention to use ISM will be.

Now that the DTPB constructs have been addressed, the method for the operationalization of the study will be presented.

\section{METHOD}

A cross-sectional survey was conducted among employees from various organizations. The survey was conducted from September 2016 to May 2019 in Germany. Participants and their organizations had to meet certain criteria; therefore, purposive sampling was used for organization recruitment (Etikan, Musa, \& Alkassim, 2016). First, organizations had to have already implemented some form of ISM technology. The researchers contacted 346 organizations to participate in the study. Of these 346 , seven organizations - of various sizes ranging from 300 to more than 100,000 employees and from different industries such as retail, production, consulting, and engineering - were eligible to participate in the study. Second, participants needed to have access to ISM technologies, and as this study looks at ISM usage intention from the employees' perspective, participants needed to have a function lower than middle management. The organizations' contact person determined which employees would be eligible to participate in the study. The survey took form as an online questionnaire. An email explaining the survey with a link to the questionnaire was sent to the organizations' contact person who in turn forwarded the 
email to all eligible employees. Participants were guaranteed anonymity, and confidentiality was assured by informing participants that results would be reported only in the form of aggregated data.

\section{A. Sample}

445 participants fully completed the questionnaire. After the data was cleaned (see Appendix for detailed cleaning procedure), a combined total of 409 participants were left for analysis. The sample consisted of $87 \%$ full-time employees, $6 \%$ part-time employees, $4 \%$ apprentices, and $3 \%$ other employees. The duration of employment ranged from "below 1 year" at $14 \%$, "1 year to below 3 years" at $18 \%$, "3 years to below 6 years" at $18 \%$, and "6 years or longer" at $50 \%$. Of the 409 participants, $76 \%$ were male and $23 \%$ were female. The median age of participants in the sample was 38 years.

\section{B. Measures}

The following constructs used a 5-point Likert-type response scale ranging from 1 "does not apply at all" to 5 "fully applies". First, participants were asked the question: "Do you already use internal social media in your daily work?" This was done to be able to identify group differences between users $(\mathrm{N}=262)$ and non-users $(\mathrm{N}=147)$.

The dependent variable was the intention to use ISM, which was measured with four items that were adapted from the DTPB (Taylor $\&$ Todd, 1995) (users: $\alpha=0.926, \mathrm{~m}=3.99$, sd=1.09; non-users: $\alpha=0.914, \mathrm{~m}=3.15$, sd=1.04) by asking participants of their intention to use ISM usage in general, as well as, with other employees in the organization. Here it is important to note that since users already use ISM, users were asked about their intention to continue their use in the next quarter.

Acceptance was measured through the constructs: perceived usefulness, perceived ease of use, and the compatibility of ISM. These constructs were used and adapted from the DTPB (Taylor \& Todd, 1995). Usefulness was measured using three items (users: $\boldsymbol{\alpha}=0.900, \mathrm{~m}=4.01$, $\mathrm{sd}=0.95$; non-users: $\boldsymbol{\alpha}=0.918, \mathrm{~m}=2.98$, sd=1.04) asking participants' opinion of ISM. Ease of Use was measured using two items (users: $\alpha=0.696, \mathrm{~m}=4.02$, $\mathrm{sd}=0.83, \mathrm{~N}=262$; non-users: $\alpha=0.690, \mathrm{~m}=3.50, \mathrm{sd}=1.03$ ) asking participants how easy it would be for them to use ISM. Compatibility was measured using three items (users: $\boldsymbol{\alpha}=0.915, \mathrm{~m}=3.69$, $\mathrm{sd}=0.98$; non-users: $\boldsymbol{\alpha}=0.875, \mathrm{~m}=3.10, \mathrm{sd}=1.00$ ) by asking participants how ISM would fit with their job.

Social norms were measured through constructs that were adapted from a study that looked at norms from the TPB regarding social injunctive and descriptive norms (Park \& Smith, 2007). These two types of norms were also measured in regards to the two most influential groups within organizations: superiors and peers. Perceived Superior Usage Support was measured with four items (users: $\boldsymbol{\alpha}=0.701$, $\mathrm{m}=3.78, \mathrm{sd}=0.74$; non-users: $\boldsymbol{\alpha}=0.625, \mathrm{~m}=3.24, \mathrm{sd}=0.66$ ) asking participants' opinion of how ISM usage is viewed within the organization by upper management and direct supervisors. Perceived Peer Usage Support was measured with four items (users: $\boldsymbol{\alpha}=0.745, \mathrm{~m}=3.59$, sd=0.75; nonusers: $\boldsymbol{\alpha}=0.685, \mathrm{~m}=3.25, \mathrm{sd}=0.67)$ asking participants' opinion of how ISM usage is viewed within the organization by direct colleagues and other employees. Perceived Superior
Usage Behavior was measured with four items (users: $\boldsymbol{\alpha}=$ 0.661, $\mathrm{m}=3.22$, $\mathrm{sd}=0.91$; non-users: $\boldsymbol{\alpha}=0.764, \mathrm{~m}=2.85$, $\mathrm{sd}=0.85$ ) asking participants' opinion of how ISM is used within the organization by upper management and direct supervisors. Perceived Peer Usage Behavior was measured with four items (users: $\boldsymbol{\alpha}=0.736, \mathrm{~m}=3.67$, sd=0.87; nonusers: $\boldsymbol{\alpha}=0.815, \mathrm{~m}=3.04, \mathrm{sd}=0.84$ ) asking participants' opinion of how ISM is used within the organization among the groups' direct colleagues and other employees.

Behavioral Control was measured using five items that were adapted from the DTPB (Taylor \& Todd, 1995) asking participants about their perceived ISM usage ability. However, due to poor internal consistency, the item regarding trainings was omitted, leaving four items (users: $\boldsymbol{\alpha}=0.697$, $\mathrm{m}=4$.21, sd=0.67; non-users: $\boldsymbol{\alpha}=0.799, \mathrm{~m}=3.82$, $\mathrm{sd}=0.97$ ) for measurement. Nevertheless, as the findings of a previous qualitative study (Werling, 2020) indicated that the perceived amount of adequate training was important, training was tested separately using one item (users: $\mathrm{m}=2.97$, $\mathrm{sd}=1.4$; nonusers: $\mathrm{m}=2.37, \mathrm{sd}=1.3$ ).

\section{RESULTS}

In order to better influence employees that do not use ISM technologies, separate models were calculated for both users and non-users using multiple regression analyses to identify possible differing influencing factors for non-users. As suggested by Hayes (2018), the scales were mean-centered to form composites and reduce the likelihood of multicollinearity. A two-tailed test was used to ensure the significance of the standardized coefficients for main effects. Results were controlled for possible influences due to gender, age, organizational tenure, and contract type. In the following, the results of our theoretical model regarding users (see Table I) and non-users (see Table II) will be presented and discussed.

Regarding acceptance, the first dimension in our DTPB adapted model, the perceived usefulness of ISM increased employees' usage intention for both users and non-users (users: $\beta=0.32, p<0.001 /$ non-users: $\beta=0.51, p<0.001$ ), thereby, showing support for hypothesis H1a. The second aspect of acceptance, perceived ease of use, did not show to have a significant influence on usage intention (users: $\beta=$ $0.05, \mathrm{p}>0.05 /$ non-users: $\beta=-0.07, \mathrm{p}>0.05$ ); thus, H1b was rejected. The final aspect of ISM acceptance, the perceived compatibility of ISM, also showed to have an impact on both users and non-users (users: $\beta=0.22, \mathrm{p}<0.01 /$ non-users: $\beta=0.27, p<0.001$ ); hence, H1c was supported. This shows that both the perceived usefulness and compatibility of ISM technologies are driving factors in predicting usage intention.

In looking at the injunctive social norms, the perceived superior usage support did not affect the intention to use ISM (users: $\beta=0.11, \mathrm{p}>0.05 /$ non-users: $\beta=0.01, \mathrm{p}>0.05$ ); hence, hypotheses $\mathrm{H} 2$ a could not be supported. However, the perceived peer usage support did have a slight impact on usage intention for users but not for non-users (users: $\beta=$ $0.14, \mathrm{p}<0.05 /$ non-users: $\beta=-0.03, \mathrm{p}>0.05$ ); thus, $\mathrm{H} 2 \mathrm{~b}$ could only be partially supported. Concerning the descriptive norms, the perceived superior usage behavior did not have a significant influence on ISM usage intention (users: $\beta=$ - 
$0.10, \mathrm{p}>0.05 /$ non-users: $\beta=0.03, \mathrm{p}>0.05)$; hence, $\mathrm{H} 2 \mathrm{c}$ could not be supported. However, the perceived peer usage behavior did increase usage intention for users but not for non-users (users: $\beta=0.39, p<0.001 /$ non-users: $\beta=0.12$, $p$ $>0.05$ ); thus, H2d could only be partially supported. This would imply that the more peers are perceived to support and use ISM, the more likely employees will intend to use these technologies.

TABLE I: RESULtS OF MULTIPLE REGRESSION ANALYSIS FOR USERS' INTENTION TO USE ISM

\begin{tabular}{|c|c|c|c|}
\hline & B & $\overline{\mathrm{SE}}$ & 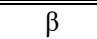 \\
\hline Constant & 0.37 & 0.37 & \\
\hline \multicolumn{4}{|l|}{ Acceptance } \\
\hline Perceived Usefulness & 0.37 & 0.08 & $0.32 * * *$ \\
\hline Perceived Ease of Use & -0.07 & 0.08 & -0.05 \\
\hline Perceived Compatibility & 0.25 & 0.08 & $0.22 * *$ \\
\hline \multicolumn{4}{|l|}{ Social Norms } \\
\hline Superior Usage Support & 0.16 & 0.10 & 0.11 \\
\hline Peer Usage Support & -0.21 & 0.09 & $-0.14 *$ \\
\hline Superior Usage Behavior & -0.12 & 0.08 & -0.10 \\
\hline Peer Usage Behavior & 0.48 & 0.08 & $0.39 * * *$ \\
\hline \multicolumn{4}{|l|}{ Behavioral Control } \\
\hline ISM Usage Ability & -0.02 & 0.10 & -0.01 \\
\hline Training & 0.12 & 0.04 & $0.15^{* *}$ \\
\hline Adjusted R2 & & $0.51 * * *$ & \\
\hline \multicolumn{4}{|l|}{$N=262$} \\
\hline \multicolumn{4}{|c|}{$* \mathrm{p}<0.05 ; * * \mathrm{p}<0.01 ; * * * \mathrm{p}<0.001$} \\
\hline \multicolumn{4}{|c|}{$\begin{array}{l}\text { Employment type, employment duration, gender, and age were all } \\
\text { controlled for effects. }\end{array}$} \\
\hline
\end{tabular}

TABLE II: RESULTS OF MULTIPLE REGRESSION ANALYSIS FOR NONUSERS' INTENTION TO USE ISM

\begin{tabular}{|c|c|c|c|}
\hline & B & $\overline{\mathrm{SE}}$ & $\beta$ \\
\hline Constant & -0.12 & 0.43 & \\
\hline \multicolumn{4}{|l|}{ Acceptance } \\
\hline Perceived Usefulness & 0.51 & 0.09 & $0.51 * * *$ \\
\hline Perceived Ease of Use & -0.07 & 0.09 & -0.07 \\
\hline Perceived Compatibility & 0.28 & 0.08 & $0.27 * * *$ \\
\hline \multicolumn{4}{|l|}{ Social Norms } \\
\hline Superior Usage Support & 0.02 & 0.12 & 0.01 \\
\hline Peer Usage Support & -0.03 & 0.11 & -0.03 \\
\hline Superior Usage Behavior & 0.04 & 0.10 & 0.03 \\
\hline Peer Usage Behavior & 0.14 & 0.11 & 0.12 \\
\hline \multicolumn{4}{|l|}{ Behavioral Control } \\
\hline ISM Usage Ability & 0.15 & 0.08 & 0.14 \\
\hline Training & 0.02 & 0.05 & 0.02 \\
\hline Adjusted R2 & & $0.63 * * *$ & \\
\hline \multicolumn{4}{|l|}{$\mathrm{N}=147$} \\
\hline \multicolumn{4}{|c|}{$* \mathrm{p}<0.05 ; * * \mathrm{p}<0.01 ; * * * \mathrm{p}<0.001$} \\
\hline \multicolumn{4}{|c|}{$\begin{array}{l}\text { Employment type, employment duration, gender, and age were all } \\
\text { controlled for effects. }\end{array}$} \\
\hline
\end{tabular}

In terms of behavioral control conditions, the perceived usage ability did not affect usage intention of ISM (users: $\beta=-0.01, \mathrm{p}>0.05$ / non-users: $\beta=0.14, \mathrm{p}>0.05$ ); however, the results of the perceived support through adequate trainings (users: $\beta=0.15, p<0.01 /$ non-users: $\beta=0.02, p>$ 0.05 ) was mixed with usage intention increasing for users, but not for non-users. Thereby, hypothesis H3 could only be partially supported. This suggests that although employees feel confident in their ability to use ISM technologies, trainings for these technologies are still a relevant factor in usage intention. The adjusted $\mathrm{R}$ square for users is 0.51 and for non-users 0.63 with both being significant.

In this chapter, the study results were presented. Next, these results, as well as both theoretical and practical implications of the study, followed by study conclusions will be discussed.

\section{DISCUSSION}

As expected, the results of the adapted theoretical model showed that acceptance - specifically the perceived usefulness and compatibility of ISM technologies - is a key influencing factor for the usage of ISM for both users and non-users. The perceived ease of use did not have a significant influence on usage intention, perhaps because participants perceived ISM as already being easy to use as shown in previous research (Haddud, Dugger, \& Gill, 2016). These findings suggest that both users and non-users would intend to use ISM if they found it to be useful and compatible with their jobs.

Concerning social norms, only the perceived peer social norms - especially peers' usage behavior - showed to be a key influencing factor for users, but not for non-users. This implies that participants which perceived their colleagues to use ISM felt more social pressure to use ISM themselves. From the results we can see that users felt more social pressure to use ISM themselves when they perceived their colleagues to be using ISM. Based on this study's results, it is not possible to determine why non-users' perceived social norms were not significant. One possible reason for this could be that non-users' colleagues and superiors simply did not use ISM enough causing non-users to perceive ISM as having little importance or priority. Another possibility is that nonusers did not perceive the added benefits of using ISM to outweigh the additional effort involved in using and learning a new technology.

Regarding behavioral control factors, only trainings showed to be a key influencing factor for users, but not nonusers, implying that participants who felt that they received adequate trainings were more likely to use ISM. The importance of the perceived adequate trainings was shown since actual users which felt that they received adequate trainings were more likely to intend to use ISM. It is of course possible that the quality of the trainings had in impact on nonusers' perceptions of ISM. If the trainings did not clearly show the benefits of how ISM can support individual employees in the own work processes, then it is possible that employees were not convinced of the advantages of using ISM. Thus, non-users thought that they received adequate trainings, but it is possible that the quality of the trainings was lacking. This could explain why trainings for users was significant and not for non-users.

\section{A. Theoretical Implications and Future Research Recommendations}

While it is important to know what factors help influence those who already use a certain communication medium, it is more important to understand how those that do not use that medium can be better influenced. If not, then organizations not only miss out on the potential benefits of employees using ISM technologies but also risk wasted resources in implementing these technologies. This study makes unique advancements to previous literature by extending the DTPB. This study shows that not only with users but also non-users there are differences concerning social norms. This could 
explain the controversy regarding the use of the social norms construct in predicting usage intention. The study's results support researchers claim that both injunctive and descriptive norms be taken into consideration. It is possible that due to these mixed findings, some researchers have chosen to exclude them altogether as can be seen in recent studies in technology adoption (Lin \& Lin, 2019; Prinsloo, 2018). Thus, this study highlights the need for future researchers to consider the complexities of social norms in organizations, and how they can affect not only technology adoption but also behavioral outcomes of employees.

\section{B. Practical Implications and Recommendations}

This study also offers practical implications for organizations. Since the perceived usefulness and perceived compatibility of ISM showed to be the most influencing factor for both users and non-users, organizations should promote employees' usage of ISM technologies. By showing employees how their colleagues are using ISM within their jobs, organizations can increase the likelihood that employees will find ISM to be useful and compatible with their jobs and thus increasing the likelihood that employees will intend to use ISM technologies. This could be combined with offering high quality trainings and/or information sessions showing the individual benefits and advantages of using ISM.

\section{Limitations}

This study has some limitations that open potential for future research. A large number of organizations were contacted to participate in this study; however, only a few of the organizations had these technologies in place. Regardless of this, organizations of various sizes from various industries were recruited, allowing for more diverse outcomes. The cross-sectional design of the study could also be considered a limitation to some; however, a cross-sectional design was deemed appropriate for the following reasons. First, an appropriate temporal delay for multiple data gathering time points is unknown. Second, it would be difficult to control for nonmethodological factors among different organizations, such as specific and varying work processes in the participating organizations (Podsakoff, MacKenzie, \& Podsakoff, 2011; Spector, 2019).

\section{CONCLUSION}

Management faces the challenge of understanding reasons for employees' usage of ISM technologies, but especially for those that do not use these communication technologies. This study identifies factors that can help to persuade such employees to implement these technologies in their everyday work, allowing organizations to not only save but optimize precious resources. As the trend for organizations to go digital in their operations continues to grow, management must have more understanding as to how it can better persuade its employees to use new communication technologies. By extending the DTPB to include both injunctive and descriptive social norms, this study offers the opportunity to better understand internal communication technology usage in future research.

\section{APPENDIX}

\section{A. Criteria Ensuring Quality of the Survey Data}

A total of 445 participants completed the questionnaire. Prior to the analysis, data quality was thoroughly checked taking into account the following criteria:

An attention check in form of the following item: "If I am reading this question carefully, I will check 'does not apply at all' here." All participants that did not check 'does not apply at all' were removed from the analysis. A self-reported "use-me" question at the end of the questionnaire was used. Participants were asked: "Finally, we would like to point out that it is essential for our research to evaluate only responses from people who have given the study their full attention and have honestly answered all questions. Should we use your data from the survey?" Participants that selected "no" were removed from the analysis.

Furthermore, participants which used 'straight-lining' were also removed from the analysis. Finally, 409 complete interviews remained in the data set for the analyses.

\section{B. Investigated Variables and Corresponding Items for their Operationalization}

TABLE III: INVESTIGATED VARIABLES AND CORRESPONDING ITEMS FOR THEIR OPERATIONALIZATION

\section{Intention to use internal social media technologies}

USER: $\boldsymbol{\alpha}=.926, m=3.99, s d=1.09, N=262 ; N O N-U S E R: \alpha=.914$,

$m=3.15, s d=1.04, N=147$

I would use internal social media./ I plan to use internal social media in the next Quarter.

I would regularly use internal social media./ I plan to regularly use internal social media in the next quarter.

I plan to use internal social media in the future to communicate in general with other employees.

I plan to use internal social media in the future to collaborate with direct colleagues.

\section{Acceptance}

Usefulness

USER: $\boldsymbol{\alpha}=.900, m=4.01, s d=.95, N=262 ; N O N-U S E R: \boldsymbol{\alpha}=.918$, $m=2.98, s d=1.04, N=147$

The usage of internal social media is/ would be a good idea.

The usage of internal social media alleviates/ would alleviate my work. On the whole, the usage of internal social media is/ would be an advantage.

Ease of Use

USER: $\boldsymbol{\alpha}=.696, m=4.02, s d=.83, N=262 ; N O N-U S E R: \boldsymbol{\alpha}=.690$, $m=3.50, s d=1.03, N=147$

I feel/ would feel confident in using internal social media.

It is/ would be easy for me to use internal social media.

Compatibility

USER: $\boldsymbol{\alpha}=.915, m=3.69, s d=.98, N=262 ; N O N-U S E R: \boldsymbol{\alpha}=.875$, $m=3.10, s d=1.00, N=147$

The usage of internal social media is/ would be possible in areas of my work.

The usage of internal social media fits/ would fit in my workflow. The options that internal social media offers fits/ would fit in how I work.

Social Norms

Perceived Superior Usage Support (Injunctive Norm) USER: $\boldsymbol{\alpha}=.701, m=3.78, s d=.74, N=262 ; N O N-U S E R: \boldsymbol{\alpha}=.625$, $m=3.24, s d=.66, N=147$

Upper management thinks the usage of internal social media is/ would be an advantage.

Upper management judges/ would judge the usage of internal social media critical.*

My direct superior thinks the usage of internal social media is/ would be an advantage. 
My direct supervisor judges/ would judge the usage of internal social media critical.*

Perceived Peer Usage Support (Injunctive Norm)

USER: $\boldsymbol{\alpha}=.745, m=3.59, s d=.75, N=262 ; N O N-U S E R: \boldsymbol{\alpha}=.685$,

$m=3.25, s d=.67, N=147$

My direct colleagues think the usage of internal social media is/would be an advantage.

My direct colleagues judge/ would judge the usage of internal social media critical.*

Other employees think the usage of internal social media is/ would be an advantage.

Other employees judge/ would judge the usage of internal social media critical.*

Perceived Superior Usage Behavior (Descriptive Norm)

USER: $\boldsymbol{\alpha}=.661, m=3.22, s d=.91, N=262 ; N O N-U S E R: \boldsymbol{\alpha}=.764$,

$m=2.85, s d=.85, N=147$

Upper management thinks that I should use internal social media.

I know that upper management uses/would use internal social media.

My direct superior thinks that I should use internal social media.

I know that my direct superior uses/would use internal social media.

Perceived Peer Usage Behavior (Descriptive Norm)

USER: $\boldsymbol{\alpha}=.736, m=3.67, s d=.87, N=262 ; N O N-U S E R: \boldsymbol{\alpha}=.815$,

$m=3.04, s d=.84, N=147$

My direct colleagues think that I should use internal social media.

I know that my direct colleagues use/would use internal social media.

Other employees think that I should use internal social media.

I know that other employees use/would use internal social media.

\section{Behavioral Control}

Internal Social Media Usage Ability

USER: $\boldsymbol{\alpha}=.697, m=4.21, s d=.67, N=262 ; N O N-U S E R: \boldsymbol{\alpha}=.799$,

$m=3.82, s d=.97, N=147$

I have basic knowledge in using internal social media.

I can/ could independently use internal social media.

I can/ could handle using internal social media, even if nobody is

available to show me.

I have the necessary technology resources to use internal social media.

Training

USER: $m=2.97, s d=1.4, N=262 ; N O N-U S E R: m=2.37, s d=1.3, N=147$

I received/would receive adequate support through trainings to use

internal social media.

\section{ACKNOWLEDGMENT}

K. Werling thanks Dr. Berend Barkela, Dr. Lukas Otto, Dr. Corinna O'Schatz and Dr. Fabian Thomas for their constructive critique and feedback for this paper.

\section{CONFLICT OF INTEREST}

Authors declare that they do not have any conflict of interest.

\section{REFERENCES}

Ajzen, I. (1985). From intentions to actions: A theory of planned behavior. In J. Kuhl \& J. Beckmann (Eds.), Action control: From Cognition to Behavior (pp. 11-39). New York: Springer Verlag.

Ajzen, I. (1991). The theory of planned behavior. Organizational Behavior and Human Decision Processes, 50(2), 179-211. https://doi.org/10.1016/0749-5978(91)90020-T.

Alm, J., Schulze, W. D., von Bose, C., \& Yan, J. (2019). Appeals to Social Norms and Taxpayer Compliance. Southern Economic Journal, 86(2), 638-666. https://doi.org/10.1002/soej.12374.

Benitez, J., Chen, Y., Teo, T. S. H., \& Ajamieh, A. (2018). Evolution of the impact of e-business technology on operational competence and firm profitability: A panel data investigation. Information \& management 55(1), 120-130. https://doi.org/10.1016/j.im.2017.08.002.

Benitez, J., Llorens, J., \& Braojos, J. (2018). How information technology influences opportunity exploration and exploitation firm's capabilities. Information \& management, 55(4), 508-523. https://doi.org/10.1016/j.im.2018.03.001.

Carfora, V., Cavallo, C., Caso, D., Del Giudice, T., De Devitiis, B., Viscecchia, R., Nardone, G. \& Cicia, G. (2019). Explaining consumer purchase behavior for organic milk: Including trust and green selfidentity within the theory of planned behavior. Food Quality and Preference, 76, 1-9. https://doi.org/10.1016/j.foodqual.2019.03.006.

Chan, D. K. C., Stenling, A., Yusainy, C., Hikmiah, Z., Ivarsson, A., Hagger, M. S., Rhodes, R.E. \& Beauchamp, M. R. (2019). Editor's Choice: Consistency tendency and the theory of planned behavior: randomized controlled crossover trial in a physical activity context. Psychology \& Health, 35(6) 665-684. https://doi.org/10.1080/08870446.2019.1677904

Cheng, E. W. L. (2019). Choosing between the theory of planned behavior (TPB) and the technology acceptance model (TAM). Educational Technology Research and Development, 67(1), 21-37. https://doi.org/10.1007/s11423-018-9598-6.

Chin, P. Y., Evans, N., Liu, C. Z., \& Choo, K.-K. R. (2020). Understanding Factors Influencing Employees' Consumptive and Contributive Use of Enterprise Social Networks. Information Systems Frontiers, 22, 1357 1376. https://doi.org/10.1007/s10796-019-09939-5.

Davis, F. D. (1989). Perceived usefulness, perceived ease of use, and user acceptance of information technology. MIS quarterly, 13(3), 319-340. https://doi.org/10.2307/249008.

Davis, F. D., Bagozzi, R. P., \& Warshaw, P. R. (1989). User acceptance of computer technology: a comparison of two theoretical models. Management science, 35(8), 982-1003. https://doi.org/10.1287/mnsc.35.8.982.

El Ouirdi, A., El Ouirdi, M., Segers, J., \& Henderickx, E. (2015). Employees' use of social media technologies: a methodological and thematic review. Behaviour \& Information Technology, 34(5), 454-464. https://doi.org/10.1080/0144929X.2015.1004647.

Etikan, I., Musa, S. A., \& Alkassim, R. S. (2016). Comparison of convenience sampling and purposive sampling. American Journal of Theoretical and Applied Statistics, 5(1), 1-4. https://doi.org/10.11648/j.ajtas.20160501.11.

Ewing, M., Men, L. R., \& O’Neil, J. (2019). Using Social Media to Engage Employees: Insights from Internal Communication Managers. International Journal of Strategic Communication, 13(2), 110-132. https://doi.org/10.1080/1553118X.2019.1575830.

Haddud, A., Dugger, J. C., \& Gill, P. (2016). Exploring the impact of internal social media usage on employee engagement. Journal of Social Media for Organizations, 3(1), 1-23.

Janes, S.H., Patrick, K., \& Dotsika, F. (2014). Implementing a social intranet in a professional services environment through Web 2.0 technologies. The Learning Organization, 21(1), 26-47. https://doi.org/10.1108/TLO-11-2012-0068.

Hayes, A. F. (2018). Introduction to mediation, moderation, and conditional process analysis: A regression-based approach (Second ed.). New York, NY: Guilford Publications.

Jacobson, R., Mortensen, C., \& Cialdini, R. (2011). Bodies obliged and unbound: Differentiated response tendencies for injunctive and descriptive social norms. Journal of personality and social psychology, 100(3), 433-448. https://doi.org/10.1037/a0021470.

Jallow, A. K., Demian, P., Anumba, C. J., \& Baldwin, A. N. (2017). An enterprise architecture framework for electronic requirements information management. International journal of information management, 37(5), 455-472. https://doi.org/10.1016/j.ijinfomgt.2017.04.005

Jimmieson, N. L., Peach, M., \& White, K. M. (2008). Utilizing the Theory of Planned Behavior to Inform Change Management: An Investigation of Employee Intentions to Support Organizational Change. The Journal of Applied Behavioral Science, 44(2), 237-262. https://doi.org/10.1177/0021886307312773.

Kandlousi, N. S. A. E., Ali, A. J., \& Abdollahi, A. (2010). Organizational citizenship behavior in concern of communication satisfaction: The role of the formal and informal communication. International Journal of Business and Management, 5(10), 51-61.

Karanges, E., Johnston, K., Beatson, A., \& Lings, I. (2015). The influence of internal communication on employee engagement: A pilot study. Public Relations Review, 41(1), 129-131. https://doi.org/10.1016/j.pubrev.2014.12.003.

Khalili, A., Abbadi, A., \& Ismail, M. Y. (2019). Perspective of social media as an organisational $\mathrm{KM}$ tool: contemporary literature review. International Journal of Knowledge and Learning, 13(1), 10-24. https://doi.org/10.1504/IJKL.2019.099353.

Khatri, I. (2019). Information Technology in Tourism \& Hospitality Industry: A Review of Ten Years' Publications. Journal of Tourism and $\begin{array}{llll}\text { Hospitality } & \text { Education, } & \text { 74-87. }\end{array}$ https://doi.org/10.3126/jthe.v9i0.23682.

King, W. R., \& He, J. (2006). A meta-analysis of the technology acceptance 
model. Information \& management, 43(6), 740-755. https://doi.org/10.1016/j.im.2006.05.003.

Lebek, B., Uffen, J., Neumann, M., Hohler, B., \& Breitner, M. H. (2014). Information security awareness and behavior: a theory-based literature review. Management Research Review, 37(12), 1049-1092. https://doi.org/10.1108/MRR-04-2013-0085.

Leidner, D. E., Gonzalez, E., \& Koch, H. (2018). An affordance perspective of enterprise social media and organizational socialization. The Journal of Strategic Information Systems, 27(2), 117-138. https://doi.org/10.1016/j.jsis.2018.03.003.

Leonardi, P. (2014). Social media, knowledge sharing, and innovation: Toward a theory of communication visibility. Information systems research, 25(4), 796-816. doi:https://doi.org/10.1287/isre.2014.0536.

Leonardi, P. (2015). Ambient awareness and knowledge acquisition: using social media to learn 'who knows what'and 'who knows whom'. MIS quarterly, 39(4), 747-762. https://www.jstor.org/stable/26628649.

Leonardi, P., Huysman, M., \& Steinfield, C. (2013). Enterprise Social Media: Definition, History, and Prospects for the Study of Social Technologies in Organizations. Journal of Computer-Mediated Communication, 19(1), 1-19. https://doi.org/10.1111/jcc4.12029.

Li, A., Figg, G., \& Schüz, B. (2019). Socioeconomic Status and the Prediction of Health Promoting Dietary Behaviours: A Systematic Review and Meta-Analysis Based on the Theory of Planned Behaviour. Applied Psychology: Health and Well-Being, 11(3), 382-406. https://doi.org/10.1111/aphw.12154.

Lin, T.-C., \& Lin, S. (2019). A tripartite acceptance model for Enterprise 2.0 systems. Quarterly Review of Business Disciplines, 6(1), 59-78.

Madsen, V.T. (2018). Participatory communication on internal social media - a dream or reality? Corporate communications: An international journal, 23(4), 614-628. https://doi.org/10.1108/CCIJ-04-2018-0039.

Neves, P., \& Eisenberger, R. (2012). Management communication and employee performance: The contribution of perceived organizational support. Human Performance, 25(5), 452-464 https://doi.org/10.1080/08959285.2012.721834

Oostervink, N., Agterberg, M., \& Huysman, M. (2016). Knowledge Sharing on Enterprise Social Media: Practices to Cope with Institutional Complexity. Journal of Computer-Mediated Communication, 21(2), 156-176. https://doi.org/10.1111/jcc4.12153.

Park, H. S., \& Smith, S. W. (2007). Distinctiveness and Influence of Subjective Norms, Personal Descriptive and Injunctive Norms, and Societal Descriptive and Injunctive Norms on Behavioral Intent: A Case of Two Behaviors Critical to Organ Donation. Human $\begin{array}{llll}\text { Communication } & \text { Research, } & 33(2), & 194-218\end{array}$ https://doi.org/10.1111/j.1468-2958.2007.00296.x.

Podsakoff, P. M., MacKenzie, S. B., \& Podsakoff, N. P. (2011). Sources of Method Bias in Social Science Research and Recommendations on How to Control It. Annual review of psychology, 63(1), 539-569. https://doi.org/10.1146/annurev-psych-120710-100452.

Prinsloo, C. (2018). Employees' Acceptance of E-Newsletters for Organisational Information Transfer. Communication, 44(2), 88-112. https://doi.org/10.1080/02500167.2018.1483959.

Regmi, R., Zhang, Z., Khanal, S., Zhang, H., \& Kim, J. (2019). An empirical study on user acceptance of ERP system by international students in Chinese HEIs: A TAM approach. International Journal of Higher Education Management, 6(1), 67-82. https://doi.org/10.24052/IJHEM/V06N01/ART-5.

Riedl, D., \& Betz, F. (2012). Intranet 2.0 Based Knowledge Production: An Exploratory Case Study on Barriers for Social Software. Paper presented at the The fourth international conference on information, process, and knowledge management.

Robbins, S. P., \& Judge, T. (2018). Essentials of organizational behavior (14 ed.). Edinburgh: Pearson

Schneider, F. M., Aehling, K., Maier, M., \& Bacherle, P. (2010). BusinessTV wirkt... oder etwa nicht? Ein methodisches Idealfallszenario und empirische Ergebnisse zur Evaluation von Business-TV. In J. Woelke, M. Maurer, \& O. Jandura (Eds.), Forschungsmethoden für die Marktund Organisationskommunikation (pp. 200-220). Köln: Herbert von Halem.

Sommestad, T., Karlzén, H., \& Hallberg, J. (2019). The Theory of Planned Behavior and Information Security Policy Compliance. Journal of Computer Information Systems, 59(4), 344-353. https://doi.org/10.1080/08874417.2017.1368421.

Spector, P. (2019). Do Not Cross Me: Optimizing the Use of Cross-Sectional Designs. Journal of Business and Psychology, 34(2), 125-137. https://doi.org/10.1007/s10869-018-09613-8.

Taylor, S., \& Todd, P. (1995). Understanding information technology usage: A test of competing models. Information systems research, 6(2), 144176. https://doi.org/10.1287/isre.6.2.144.

Treem, J. W. (2015). Social Media as Technologies of Accountability:Explaining Resistance to Implementation Within
Organizations. American Behavioral Scientist, 59(1), 53-74. https://doi.org/10.1177/0002764214540506.

Urbach, N., \& Röglinger, M. (2019). Introduction to Digitalization Cases: How Organizations Rethink Their Business for the Digital Age. In: Urbach N., Röglinger M. (Eds.), Digitalization Cases. Management for Professionals (pp. 1-12). Cham: Springer. https://doi.org/10.1007/9783-319-95273-4_1.

van Vuuren, M., de Jong, M. D., \& Seydel, E. R. (2007). Direct and indirect effects of supervisor communication on organizational commitment. Corporate communications: An international journal, 12(2), 116-128 https://doi.org/10.1108/13563280710744801.

Venkatesh, V., \& Bala, H. (2008). Technology acceptance model 3 and a research agenda on interventions. Decision Sciences, 39(2), 273-315. https://doi.org/10.1111/j.1540-5915.2008.00192.x.

Venkatesh, V., Morris, M. G., Davis, G. B., \& Davis, F. D. (2003). User acceptance of information technology: Toward a unified view. MIS quarterly, 27(3), 425-478. https://doi.org/10.2307/30036540.

Werling, K. (2020). Influencing factors for employees' usage intention of internal social media communication technologies. European Journal of Business and Management Research, 5(2), 1-8 https://doi.org/10.24018/ejbmr.2020.5.2.260.

Williams, S. P., Hausmann, V., Hardy, C. A., \& Schubert, P. (2013). Enterprise 2.0 Research: Meeting the Challenges of Practice. Paper presented at the Bled eConference.

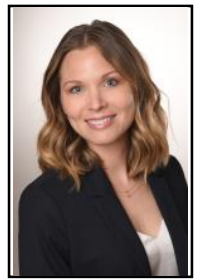

Kristen Werling (born in Pensacola, FL USA) has a $\mathrm{PhD}$ in organizational psychology and communication from the University of KoblenzLandau in Germany. She also earned her Master in Business Administration at the University of West Florida. Her research focus is on organizational psychology, organizational communication, and the implementation and usage of traditional communication and social media within organizations.

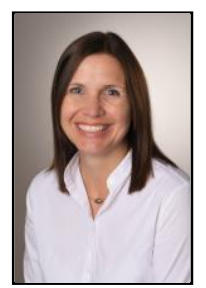

Michaela Maier has a $\mathrm{PhD}$ in media studies and is Professor at the Institute for Communication Psychology and Media Education at the University of Koblenz-Landau. Her research focus is not only on organizational communication and media usage but also political communication and media usage, scientific communication, and journalism. 